\title{
Is There a Place for Conservative Treatment of Acute Appendicitis?
}

\author{
Jamal T. Hamdi, FRCS(Ed), FACS \\ Department of Surgery, College of Medicine \\ Umm Al-Qura University, Makkah Al Mukarramah, Saudi Arabia \\ jthamdi@hotmail.com
}

\begin{abstract}
Acute appendicitis is the most common acute surgical condition of the abdomen. The diagnosis of acute appendicitis continues to present clinicians with problems despite the advances in the investigating technology. This retrospective study aims to review appendiceal histopathological records in a district hospital in Makkah in 2007. The study was based on all appendices removed during emergency appendectomies to identify the proportion of normal and mildly inflamed appendices, in addition to their sex ratio, so that a prospective study can be carried out with conservative treatment with antibiotics, if justified. The records were divided into negative, mild and severely inflamed or perforated appendix. The number of the operations was 405 , with nearly equal male and female ratio. The ratio of normal appendix was $24.2 \%$, mild appendicitis was $26.4 \%$, and severe appendicitis was $49.4 \%$. Over $50 \%$ of all emergency appendectomies were performed on normal or mildly inflamed appendix, which rises to over $60 \%$ in females alone. The number of the males with severe appendicitis is nearly $50 \%$ more than that of the females. Patients, especially females, with normal or mildly inflamed appendix, if identified before surgery, may benefit from conservative treatment with antibiotics.
\end{abstract}

Keywords: Acute, Appendicitis, Treatment, Conservative.

\section{Introduction}

Acute appendicitis is the most common severe surgical condition of the abdomen $^{[1]}$. Approximately $7 \%$ of the population will have appendicitis ${ }^{[2]}$

$\overline{\text { Correspondence } \& \text { reprint request to: }}$

Dr. Jamal T. Hamdi

P.O. Box 8343, Makkah, Saudi Arabia

Accepted for publication: 02 December 2009. Received: 05 July 2009. 
with the peak incidence occurring between the ages of 10-30 years ${ }^{[3]}$. Despite the advances in surgery over the past century, the diagnosis of acute appendicitis continues to present clinicians with problems. In 15 to 40 percent of those undergoing emergency operations for suspected appendicitis, the appendix is normal ${ }^{[4]}$. Clearly, more precision in the diagnosis is essential. Treatment of acute appendicitis has remained the same since the introduction of surgical removal of the inflamed appendix as the curative therapy in $1886^{[5]}$. The surgical goal is to operate early, before an appendiceal perforation, which increases the risk of postoperative complications to $39 \%$, as compared with $8 \%$ for simple appendicitis $^{[6]}$. Also, the removal of a normal appendix carries a post operative complication rate of $4-15 \%{ }^{[7]}$. Ultrasound (US) and computerized tomogram (CT) scan can improve the health outcome in patients with equivocal appendicitis compared with clinical evaluation alone. However, CT scan is more specific, less prone to operator bias and usually more sensitive, resulting in overall greater accuracy than $\mathrm{US}^{[8]}$. Recently some studies have shown that treatment with antibiotics alone may suffuse in the cases of mild non-perforated acute appendicitis ${ }^{[9]}$. A large prospective multicenter randomized controlled trial, over 3 years in Sweden, have shown that acute non-perforated appendicitis can be treated successfully with antibiotics alone ${ }^{[10]}$.

The dilemma facing the surgeon is the identification of those patients with mild appendicitis who may benefit from conservative treatment. As the gold standard in diagnosis of acute appendicitis is histopathology. This study aims to review the histopathological records of all appendices removed during emergency appendectomies; to identify the proportion of normal and mildly inflamed appendices; and their sex ratio so that a prospective study can be carried out with conservative treatment with antibiotics, if justified.

\section{Methodology}

This is a retrospective study based on a detailed review of all histopathological records of all the appendices, which were removed during emergency appendectomies at Hera General Hospital in Makkah from $1^{\text {st }}$ January to $31^{\text {st }}$ December 2007 . The investigator reviewed all the records with the help of a histopathology consultant. The appendices were divided into three groups according to the following categories: 
Category 1: Normal appendix; Category 2: Mildly inflamed appendix; Category 3: Severely inflamed or perforated appendix.

Acute appendicitis is define by some authors as the presence of transmural inflammation of appendix or the presence of pus in the lumen of the appendix ${ }^{[11]}$. Riber and his group ${ }^{[12]}$ in Denmark define it as an appendix, which shows one or more of the following features:

1. Granulocytes in the mucosa with focal or diffuse ulceration of the epithelium.

2. Crypt abscess with granulocytes in the epithelium.

3. Granulocytes in the lumen with an infiltration into the epithelium.

4. Granulocytes on the serosa with appendicular abscess, with or without involvement of the mucosa.

Granulocytes at the serosa or in the muscle layer without abscess and without involvement of the mucosa are not diagnosed as acute appendicitis, but as periappendicitis.

Sternberg's Diagnostic Surgical Pathology textbook ${ }^{[13]}$ divides acute appendicitis into minimal, mild or early which shows; focal collection of neutrophils within the lumen and lamina propria; or focal erosions; cryptitis or crypt abscess formation; and severe appendicitis, which shows extensive suppuration extending deep into or through the appendiceal wall.

In this present study the Mildly Inflamed Appendix is defined as: An appendix which shows one or more of the following features (Category 2):

1. Mucosal erosion with superficial inflammation

2. Crypt abscess or cryptitis

3. Perivascular inflammation with cellular infiltration of parietal wall

4. Intraluminal inflammatory exudates

However, the inflammation should not reach the features of suppuration or gangrenous changes.

Any appendix which did not show any of the above features is defined as Normal Appendix (Category 1). Whereas any appendix which showed more advanced inflammatory changes e.g., extensive suppuration 
extending deep into the wall of the appendix is defined as severe appendicitis (Category 3).

The results were tabulated and analyzed using the Excel program (Microsoft Office).

\section{Results}

During the year of 2007, there were 405 emergency appendectomies carried out in Hera General Hospital. Of these patients, 211 (52.1\%) were males and $194(47.9 \%)$ were females. The number of normal appendices was $98(24.2 \%)$ which account for $18.5 \%$ of all male appendectomies and $30.4 \%$ of all female appendectomies. The number of mild appendicitis was 107 (26.4\%) which account for $24.2 \%$ of all male appendectomies and $28.7 \%$ of all female ones. The number of severe appendicitis including perforated appendices was $200(49.4 \%)$ which account for $(57.3 \%)$ of all male appendectomies and $(40.7 \%)$ of all female.

Figure 1 shows the distribution of the 3 categories of the histopathology of the appendix among both sexes.

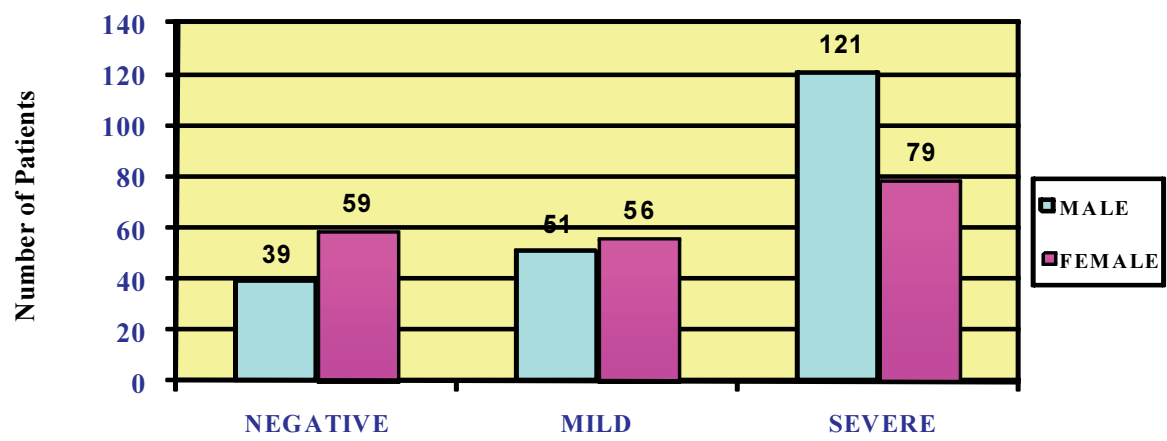

Fig. 1. The histopathology of appendix among males and females.

\section{Discussion}

Nearly over $50 \%$ of all emergency appendectomies were performed on normal or mildly inflamed appendix. This figure rises to $60 \%$ if we consider females alone. This high percentage is not unique to our hospital, as high rate of negative appendectomy was reported from many 
studies $^{[4,14]}$. These patients would definitely benefit from conservative treatment with observation and antibiotics ${ }^{[9]}$, if we can identify them preoperatively.

It was clearly shown that an in-hospital, reasonable delay did not affect the perforation rate ${ }^{[15,16]}$. Therefore, treatment with antibiotics during observation of the patient in the hospital should not increase morbidity of the condition. In spite of the advances in the diagnostic and imaging techniques, the rates of the negative findings on appendectomy have not decreased much. Clinical judgment is still the most important factor in the management of patients with suspected acute appendicitis. The routine use of CT scan or diagnostic laparoscopy for all patients who are suspected to have acute appendicitis is neither cost-effective nor safe ${ }^{[17]}$. However, the use of these two diagnostic procedures in selected controversial cases can enhance the accuracy of diagnosis, reduces the cost and reduces the rate of normal appendectomy ${ }^{[8,17]}$. Ultrasonography can be carried out with minimum delay and can yield pertinent, plus surgically relevant information. Such as confirmation of diagnosis of appendicitis, status of inflamed appendix, location and orientation of appendix; presence or absence of any associated complications, adhesions, free fluid, etc., besides suggesting alternative diagnoses, which helps in appropriate surgical planning ${ }^{[18]}$.

Despite the fact that the number of the operations is distributed equally between males and females, the number of the males with severe appendicitis is nearly $50 \%$ more than that of the females. This is in comparison with other studies, which showed equal distribution of severe and perforated appendix among females and males ${ }^{[1]}$. This result would definitely favors more conservative treatment in females.

The next step would be to identify the clinical features and investigative procedures, which would help to diagnose; mild, acute appendicitis and normal appendix with high sensitivity and specificity, hence, to be treated conservatively.

\section{Acknowledgments}

The author would like to thank Dr. Osama Hejagy, Consultant Histopathologist at Hera Hospital for his assistance in conducting this study. 


\section{References}

[1] Liu CD, McFaden DW. Acute abdomen and appendix. In: Greenfield LJ, (ed.) Surgery: Scientific Principles and Practice, Philadelphia: Lippincott-Raven, 1997. 1246-1261.

[2] Addiss DG, Shaffer N, Fowler BS, Tauxe RV. The epidemiology of appendicitis and appendectomy in the United States. Am J Epidemiol 1990; 132(5): 910-925.

[3] Schwartz SI, (ed.) Appendix. In: Principles of Surgery. New York: McGraw Hill, 1994. 1307-1318.

[4] Rao PM, Rhea JT, Novelline RA, Mostafavi AA, McCabe CJ. Effect of computed tomography of the appendix on treatment of patients and use of hospital resources. $N$ Engl $J$ Med 1998; 338(3): 141-146.

[5] Kozar RA, Roslyn JJ. The appendix. In: Schwartz SI, (ed.) Principles of Surgery. New York: McGraw Hill, 1994. p. 1307-1318.

[6] Jess P, Bjerregaard B, Brynitz S, Holst-Christensen J, Kalaja E, Lund-Kristensen J. Acute appendicitis. Prospective trial concerning diagnostic accuracy and complications. Am J Surg 1981; 141(2): 232-234.

[7] Incesu L, Coskun A, Selcuk MB, Akan H, Sozubir S, Bernay F. Acute appendicitis: MR imaging and sonographic correlation. AJR Am J Roentgenol 1997; 168(3): 669-674.

[8] Al-Khayal K, Al-Omran M. Computed tomography and ultrasonography in the diagnosis of equivocal acute appendicitis: A meta-analysis. Saudi Med J 2007; 28(2): 173-180.

[9] Liu K, Ahanchi S, Pisaneschi M, Lin I, Walter R. Can acute appendicitis be treated by antibiotics alone? Am Surg 2007; 73(11): 1161-1165.

[10] Styrud J, Eriksson S, Nilsson I. Appendectomy versus antibiotic treatment in acute appendicitis. A prospective multicenter randomized controlled trial. World J Surg; 2006; 30(6): 1033-1037.

[11] Marudanayagam R, Williams G, Rees B. Review of the pathological results of 2660 appendicectomy specimens. J Gastroenterol 2006; 41(8): 745-749.

[12] Riber C, Tønnesen H, Aru A, Bjerregaard B. Observer variation in the assessment of the histopathologic diagnosis of acute appendicitis. Scand J Gastroenterol 1999; 34(1): 46-49.

[13] Mills S, (ed.) Sternberg's Diagnostic Surgical Pathology. $4^{\text {th }}$ ed, vol 2, Lippincott Williams \& Wilkins, p. 1522.

[14] Bijnen C, van den Broek W, Bijnen A, Ruiter P, Gouma D. Implications of removing a normal appendix. Digestive Surgery 2003; 20(3): 215-221.

[15] Colson M, Skinner KA, Punnington G. High negative appendicectomy rates are no longer acceptable. Am J Surg 1997; 174(6): 723-726.

[16] Bachoo P, Mahomed A, Ninan R, Youngson G. Acute appendicitis: The continuing role for active observation. Pediatr Surg Int 2001; 17(2-3): 125-128.

[17] Khairy G. Acute appendicitis: Is removal of a normal appendix still existing and can we reduce its rate? Saudi J Gastroenterol 2009; 15(3): 167-70.

[18] Debnath J. Acute appendicitis: Is removal of a normal appendix still existing and can we reduce its rate? Saudi J Gastroenterol 2010; 16(2): 122. 


\title{
هل يوجد مكان للعلاج التحفظي لالتهاب الز ائدة الدودية ؟
}

\author{
جمال طلعث حمدي \\ قسم الجر/حة ، كلية الطب ، جامعة أم القرى

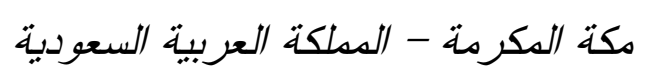

الستتخلص. التهاب الزائدة الدودية هو أكثر الحالات الجراحية

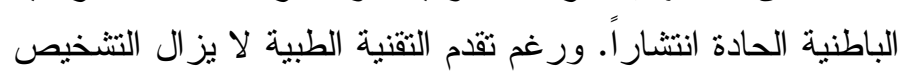

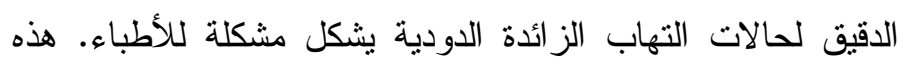

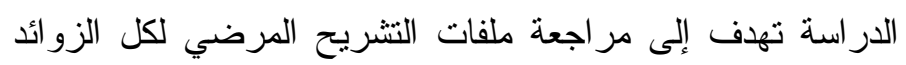

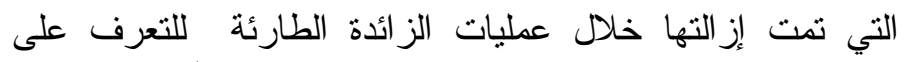

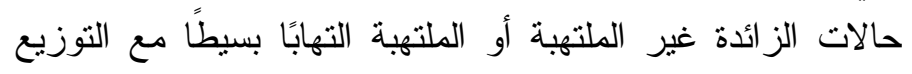

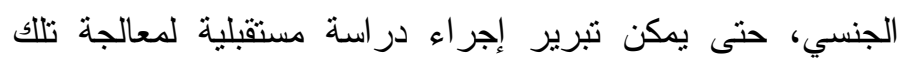

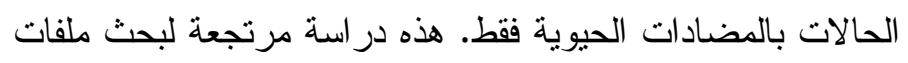

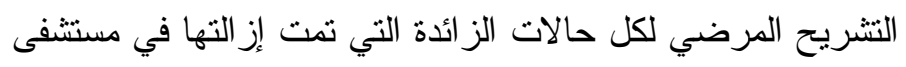

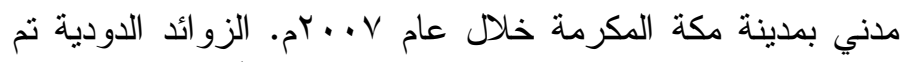

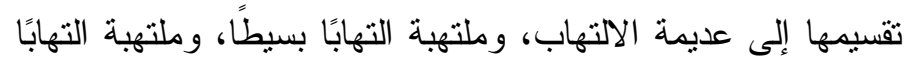

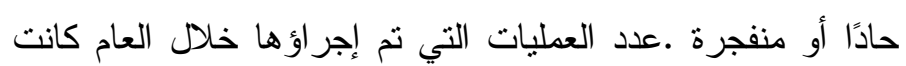

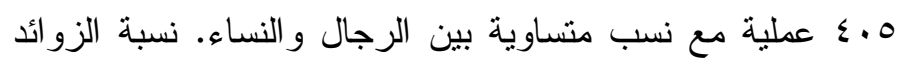

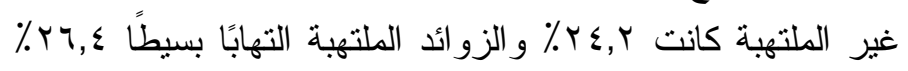

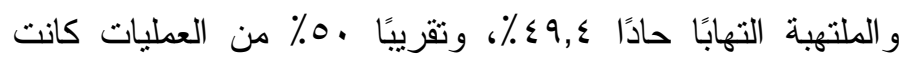

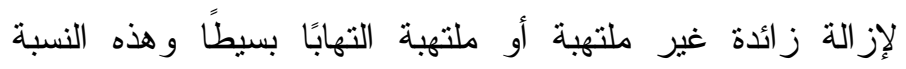

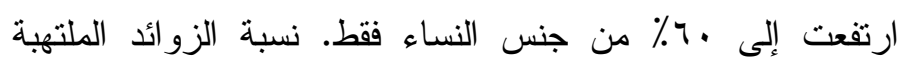

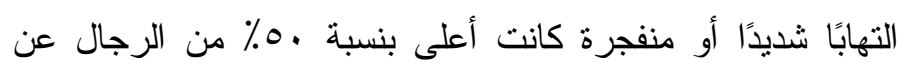

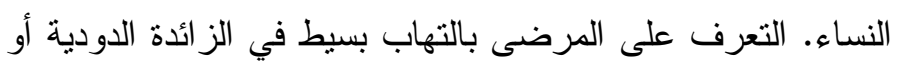

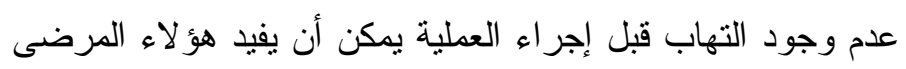

